\title{
AUF1 is involved in splenic follicular $B$ cell maintenance
}

Navid Sadri ${ }^{1}$, Jin-Yu Lu ${ }^{1,2}$, Michelle L Badura ${ }^{1}$, Robert J Schneider ${ }^{1 *}$

\begin{abstract}
Background: The adenosine/uridine-rich element (ARE)-binding protein AUF1 functions to regulate the inflammatory response through the targeted degradation of cytokine and other mRNAs that contain specific AREs in their $3^{\prime}$ noncoding region ( $3^{\prime}$ NCR). To investigate the role of AUF1 in the immune system, we characterized the lymphoid compartments of AUF1-deficient mice.

Results: Mice lacking AUF1 exhibit an altered proportion and size of splenic B cell subsets. We show prominent apoptosis in splenic B cell follicles and reduced expression of BCl-2, A1, and BCl- $X_{L}$ correlate with increased turnover and significant reduction in the number and proportion of splenic FO B cells in AUF1-deficient mice. In addition, AUF1-deficient mice exhibit a sharp decrease in splenic size and lymphocyte cellularity. Bone marrow transfer studies demonstrate that AUF1 deficiency induces cell-autonomous defects in mature B cell subsets but not in the overall number of splenocytes. Reconstitution of irradiated adult AUF1-deficient mice with wild-type bone marrow restores the proportion of $\mathrm{FO}$ and marginal zone (MZ) B cells, but does not rescue the decrease in the number of splenocytes. Functionally, AUF1-deficient mice mount an attenuated response to T cell-independent (TI) antigen, which correlates with impaired MZ B cell function.
\end{abstract}

Conclusion: These data indicate that AUF1 is important in the maintenance of splenic FO B cells and adequate humoral immune responses.

\section{Background}

The mammalian spleen functions to remove old and damaged erythrocytes, participates in the immune response, particularly against blood-borne pathogens, and is the major site for peripheral $\mathrm{B}$ cell development [1]. Immature surface immunoglobulin-expressing $B$ cells that reach the spleen from the bone marrow (referred to as 'transitional' B cells) represent developmental precursors to mature follicular (FO) B lymphocytes, the major mature $\mathrm{B}$ cell population in the spleen $[2,3]$. The other two mature $B$ cell populations consist of non-circulating splenic marginal zone (MZ) B cells that are believed to be derived from transitional cells, and B-1 cells, that are controversial in origin and are enriched in peritoneal and pleural cavities [4]. FO B cells contribute to most $\mathrm{T}$-cell dependent (TD) responses that induce germinal center (GC) development of affinity-matured long lived plasma cells and

\footnotetext{
* Correspondence: robert.schneider@nyumc.org

'Department of Microbiology, New York University School of Medicine, 550 First Avenue, New York, NY 10016, USA
}

memory B cells $[4,5]$. In contrast, MZ cells and B-1 cells are predominately responsible for the initial rapid $\mathrm{T}$-cell independent (TI) IgM antibody response and form an important line of defense against antigens and pathogens in the blood and mucosal sites $[4,6]$. More recent analysis of $\mathrm{B}$ cell populations suggests that there exist two distinguishable, long-lived, recirculating post-transitional follicular B cell populations, the mature FO B cell subset described above and a new subset referred to as FO-II B cells. The FO-II B cells differ from FO B cells in that they develop in an antigen-independent manner and may serve as a follicular precursor to both MZ B cells and FO B cells [7].

Although the precise mechanisms are still unclear, maintenance of each peripheral B cell subset is affected by the availability of resources, the local environment, and interactions with other cell types [8]. It is known that signaling through the $\mathrm{B}$ cell receptor (BCR) is required for the development and maintenance of mature splenic B cells [9]. Genetic studies utilizing knockout mouse models for various BCR complex 
components and downstream effectors clearly demonstrate that an adequate BCR signal is indispensable for the development of transitional $B$ cells and further differentiation into mature B cells [2,10-14]. Furthermore, an ongoing or 'tonic' BCR signal is required for B cells to survive $[11,15]$. This was elegantly shown using an inducible disruption of the BCR in mature B cells, which resulted in the absence of all three mature subsets [16]. In addition to BCR signaling, both the splenic microenvironment and the ability to respond to locally produced growth factors play equally important roles in the development and maintenance of mature B cells $[17,18]$.

Many short-lived mRNAs that encode cytokines and cell survival factors contain an adenosine/uridine-rich element (ARE) in the 3' non-coding region that allows for their post-transcriptional regulation by ARE-binding proteins. AUF1, also known as heterogeneous nuclear ribonucleoprotein $\mathrm{D}$, is important in promoting the decay of ARE-containing mRNAs [19-21]. In addition to mRNA turnover, AUF1 has more recently been implicated in a number of other cellular processes, including mRNA translation [22] and chromatin remodeling [23]. The physiological role of AUF1 in controlling the decay of key pro-inflammatory cytokine mRNAs, interleukin (IL) $-1 \beta$ and tumor necrosis factor (TNF)- $\alpha$, was demonstrated by the increased sensitivity of AUF1 $1^{-/-}$mice to endotoxic shock and lethality [20]. AUF1 also regulates inflammation within the skin, and AUF1 ${ }^{-/-}$mice develop atopic-like dermatitis [24].

Given the high expression of AUF1 in lymphoid organs [25], we characterized the lymphoid compartment of AUF1-deficient mice. Here we show that $\mathrm{AUF}^{-/-}$mice develop spleens of reduced size that support a roughly two-fold reduction in the number of lymphocytes. FO B cells exhibit a two-fold decrease in average half-life in $\mathrm{AUF} 1^{-/-}$mice that correlates with reduced expression of $\mathrm{Bcl}-2, \mathrm{~A} 1$, and $\mathrm{Bcl}-\mathrm{X}_{\mathrm{L}}$, as well as prominent apoptosis within splenic follicles. The increased turnover of FO B cells corresponds to their decreased frequency in AUF1 ${ }^{-1-}$ mice. Our studies indicate that AUF1 plays an important role in regulating splenic lymphocyte cellularity and FO B cell maintenance.

\section{Methods \\ Mice}

The AUF1 $1^{-/-}$mice were derived as previously described [20]. $\mathrm{RAG}^{-/-}$mice (B6.129S7-Rag $\left.1^{\mathrm{tm} 1 \mathrm{Mom}}\right)$ and CD45.1 mice (B6.SJL-Ptprc ${ }^{a}$ Pep $^{b} /$ BoyJ) were purchased from Jackson Labs. For adoptive transfer studies, $5 \times 10^{6}$ donor-derived bone marrow cells were injected intravenously into sub-lethally irradiated (500 rad) $\mathrm{RAG}^{-/-}$or into lethally irradiated (950 rad) $\mathrm{AUF}^{+/+}$and $\mathrm{AUF} 1^{-/-}$ recipient mice. Chimera mice were analyzed 10 weeks post transfer. CD45 allele expression was used to distinguish donor and recipient populations. All mice are kept under specific pathogen-free conditions. All animal protocols were approved by the NYU Institutional Animal Care and Use Committee.

\section{Flow Cytometry}

Single cell suspensions were prepared from spleen, inguinal and mesenteric lymph nodes, peritoneum lavage, bone marrow, and thymus. Cells were stained and analyzed as previously described [20]. Cell sorting was performed on a BD FACSVantage cell sorter. The following Abs were used: from BD PharMingen: anti-B220-PerCP (RA3-6B2), anti-CD3-PerCP (17A2), anti-CD4-FITC (GK1.5), anti-CD8-APC (53-6.72), anti-IgM-FITC (R660.2), anti-CD94-APC (18d3), Streptavidin-APC, Streptavidin-FITC; from Caltag: anti-CD62L-PE (MEL-14), anti-CD23-PE (B3B4); from eBioScience: anti-CD44-biotin (IM7), anti-IgM-biotin (II/41), anti-CD5-FITC (537.3), anti-CD24-PE (M1/69), anti-IgD-biotin (11-26), anti-CD21/CD35-FITC,-APC (4E3), anti-F4/80-biotin (BM8), anti-CD86-biotin (GL1), anti-CD45.1-biotin (A20), and anti-CD45.2-biotin (104). Bcl-2 levels were detected using the Bcl-2 kit (BD Pharmingen), following manufacturer's instructions. The set contains anti-Bcl-2PE (3F11) and PE-conjugated isotype control.

\section{Immunohistochemistry}

Hematoxylin and eosin stained sections were processed as previously described [20]. Germinal center staining was performed at 8 and 22 days post-immunization with TNP-Ficoll and TNP-KLH, respectively. The reagents used were from eBioscience: anti-mouse B220 (RA36B2); Cell Signaling: rabbit anti-cleaved caspase-3 (5A1); BD Pharmigen: CR1 (8C12); Vector Laboratory: biotinylated peanut agglutinin, biotinylated anti-rabbit IgG, Vectastain ABC-AP, Vectastain ABC, Vector blue AP kit, and Vector NovaRED peroxidase kit.

\section{BrdU labeling}

Mice were injected intraperitoneally with $1 \mathrm{mg}$ of BrdU (Sigma-Aldrich) and fed with drinking water containing $1 \mathrm{mg} / \mathrm{ml} \mathrm{BrdU}$ for 7 days. At 0, 7, and 21 days post BrdU administration, spleens from 3 mice per group were analyzed by FACS. Cells were stained with antiCD21-FITC and anti-CD24-PE or anti-CD23-PE, and then were fixed for $16 \mathrm{~h}$ at $4{ }^{\circ} \mathrm{C}$ with $3.4 \%$ paraformaldehyde and $0.01 \%$ Tween-20 in PBS. Cells were washed, incubated for $30 \mathrm{~min}$ at $37^{\circ} \mathrm{C}$ with $5 \mathrm{mM} \mathrm{MgCl}_{2}, 1 \%$ BSA, and DNase I (100U) in PBS, then labeled with biotinylated anti-BrdU (Br-3, Caltag) or biotinylated antiIgG control (eBioscience), and subsequently stained with Streptavidin-APC. The mean BrdU labeling at 7 days was used to calculate the labeling rate per day; $2.5 \%$ and $1.5 \%$ per day in $\mathrm{KO}$ and WT mice, respectively. To calculate average life span, the mean values were plotted as 
a function of time in the chase period, and linear regression analysis was performed to calculate time to lose the BrdU labeled population, assuming a constant pool size during the analysis.

$\mathrm{B}$ cell isolation, $\mathrm{Ca}^{2+}$ mobilization response, in vitro proliferation and survival assays

Splenic B cells were purified with the MACS CD45R microbead system and were verified by FACS to be $\geq$ $98 \% \mathrm{~B}_{2} 20^{+}$. Splenic B cells or sorted MZ B cells were loaded with $2 \mu \mathrm{M}$ Fluo-4/AM (Molecular Probes), stimulated with $10 \mu \mathrm{g} / \mathrm{ml} \mathrm{F}\left(\mathrm{ab}^{\prime}\right)_{2}$ goat anti-IgM Ab and $\mathrm{Ca}^{2+}$ mobilization was recorded on live gated cells. For proliferation assays, $2 \times 10^{4} \mathrm{MZ} \mathrm{B}$ cells were plated in triplicate in 96 well plates and stimulated with $10 \mu \mathrm{g} / \mathrm{ml}$ $\mathrm{F}\left(\mathrm{ab}^{\prime}\right)_{2}$ goat anti-IgM Ab or with $10 \mu \mathrm{g} / \mathrm{ml} \mathrm{LPS}$. For the last $8 \mathrm{~h}$ of the $48 \mathrm{~h}$ culture period the cultures were pulsed with $1 \mu \mathrm{Ci} /$ well $\left[{ }^{3} \mathrm{H}\right]$-thymidine. Incorporated radioactivity was quantified by scintillation counting. For CD86 up-regulation studies, CD86 expression was analyzed by flow cytometry before and after $24 \mathrm{~h}$ treatment with $\left.\mathrm{F}(\mathrm{ab})_{2}\right)_{2}$ goat anti-IgM Ab $(10 \mu \mathrm{g} / \mathrm{ml})$. For cell viability assays, sorted FO B cells were cultured as stated and then analyzed by flow cytometry after the addition of 7-amino-actinomycin (7-AAD) $(5 \mu \mathrm{g} / \mathrm{ml})$.

\section{Quantitative real-time RT-PCR}

FACS-sorted splenic B220 CD $21^{\text {int }} \mathrm{CD} 24^{\text {lo }}$ FO B cells were homogenized in Trizol (Invitrogen) and mRNA was extracted according to manufacturer's instructions. Bcl-2, A1, and Bcl- $\mathrm{X}_{\mathrm{L}}$ mRNA levels were determined using the Roche LightCycler system. $C_{T}$ values were used to calculate relative values and were normalized to $\mathrm{C}_{\mathrm{T}}$ values for cyclophilin $\mathrm{A}$. The following primer pairs were used:

Bcl-2, CCTGTGGATGACTGAGTACC and GAGACAGCCAGGAGAAAT

A1, CTTCAGTATGTGCTACAGGTACCCG and TGGAAACTTGTTTGTAAGCACGTCCAT

Bcl- $X_{L}$, AGAAGAAACTGAAGCAGAG and TCCGACTCACCAATACCTGCGTCCAT

BAFF, CTGTGGTCACTTACTCCAAAGG and GGATCAGATTCAACGGGTCACG

BAFF-R, GCCCAGACTCGGAACTGTCCCA and GCCCAGTAGAGATCCCTGGGTTCC

CypA, TATCTGCACTGCTAAGACTGAATG and CTTCTTGCTGGTCTTGCCATTCC.

\section{Immunoblot analysis}

Immunoblot analysis was performed according to standard protocols using ECL detection (PerkinElmer). Polyclonal antibodies to AUF1 (995) and to eIF4E (Sigma) were used.

\section{Humoral response assay}

Total pre-immune serum and TNP-specific titers were determined using the SBA Clonotyping ELISA kit from SouthernBiotech according to manufacturer instructions.
To evaluate TI-II responses, mice were immunized with $10 \mu \mathrm{g}$ TNP-Ficoll (Biosearch Technologies) and bled 7 days post immunization. To evaluate TD responses, mice were immunized with $20 \mu \mathrm{g}$ TNP-KLH (Biosearch Technologies) with adjuvant (Imject Alum, Pierce) and bled 14 days post immunization. For in vitro studies, $10^{6}$ purified B cells were stimulated with murine IL-4 (20 $\mathrm{ng} / \mathrm{ml})$ and LPS $(25 \mu \mathrm{g} / \mathrm{ml})$ for $96 \mathrm{~h}$. Immunoglobulin secretion in the supernatant was measured as described in immunization studies. RT-PCR looking for post-switch transcripts was performed as previously described [26].

\section{Statistical analysis}

Data are presented as mean \pm standard deviation. For statistical comparison of two samples, the two-tailed Student $t$-test was used for evaluation.

\section{Results}

Reduction of FO B cells in spleens of AUF1-deficient mice $\mathrm{AUF} 1^{-1-}$ mice were found to have 1.5-fold smaller spleens $(71.3 \pm 9.4 v s .52 .6 \pm 3.1 \mathrm{mg})$ and a roughly two-fold reduction in the number of splenocytes as compared to wild-type controls (Table 1). Splenocyte reduction was restricted to $\mathrm{B}$ and $\mathrm{T}$ lymphocytes, as the number of $\mathrm{F} 4 /$ $80^{+}$macrophages, $\mathrm{CD} 4^{+} \mathrm{CD}^{-}$natural killer, and CD16/ $32^{+} \mathrm{B} 220^{-}$cell populations in the spleens of $\mathrm{AUF} 1^{-1-}$ mice were unaffected (Table 1). Except for a decrease in mature $\operatorname{IgM}^{\mathrm{lo}} \operatorname{IgD}^{\text {hi }} \mathrm{B}$ cells, AUF1 ${ }^{-1-}$ mice exhibited no significant differences in the cell populations of inguinal and mesenteric lymph nodes, thymus, bone marrow or peritoneal cells (Figure 1a; Table 1), as compared to wild-type littermates. The unaltered cell subpopulations of the bone marrow and thymus in $\mathrm{AUF} 1^{-/-}$mice suggest that the reduction in splenocytes in these mice occurred at the periphery within the spleen rather than during development.

We therefore determined whether the splenocyte loss was restricted to a defined lymphocyte population. The different immature and mature splenic B cell subsets were identified based on the expression of multiple surface markers: CD21, CD23, CD24, IgM, and IgD (Figure 1a) [3]. The analyses presented were performed on mice 11-16 weeks of age, however, older mice analyzed (6 to 9 months of age) showed similar findings to younger mice. This analysis showed that the sharp reduction in splenic $B$ lymphocytes was due predominately to a two-fold reduction in the number of FO B cells (Figure 2). The absolute numbers of transitional (immature) and MZ B cells were unchanged in AUF1 ${ }^{-1-}$ mice (Figure 2). Furthermore, analysis of post-transitional precursor subsets, MZ precursor (MZP) B cells and FO-II B cells, showed no differences in absolute numbers (Figure 1b, Table 1). As a result of the decrease in total splenocytes, there was an increase in 
Table 1 Splenocyte subpopulations in AUF1 ${ }^{+/+}$, AUF1 $^{-/-}$and chimeric mice.

\begin{tabular}{|c|c|c|c|c|c|c|}
\hline & $\begin{array}{l}\text { AUF1 }^{+/+} \\
(n=10)\end{array}$ & $\begin{array}{l}\text { AUF1 }^{-/-} \\
(n=10)\end{array}$ & $\begin{array}{c}\mathrm{WT} \rightarrow \mathrm{RAG1}^{-/-} \\
(n=4)\end{array}$ & $\begin{array}{c}\mathrm{KO} \rightarrow \mathrm{RAG1}^{-/-} \\
(n=4)\end{array}$ & $\begin{array}{c}\mathrm{WT} \rightarrow \mathrm{KO} \\
(n=4)\end{array}$ & $\begin{array}{c}\mathrm{KO} \rightarrow \mathrm{WT} \\
(n=4)\end{array}$ \\
\hline Total splenocytes & $70.8 \pm 10.7$ & $41.6 \pm 7.6$ & $34.8 \pm 3.6$ & $24.7 \pm 3.8$ & $47.3 \pm 4.1$ & $73.6 \pm 7.9$ \\
\hline $\mathrm{B} 22 \mathrm{O}^{+}$ & $37.5 \pm 3.3$ & $23.4 \pm 1.5$ & $16.6 \pm 0.9$ & $10.6 \pm 1.4$ & $24.3 \pm 6.2$ & $39.7 \pm 4.3$ \\
\hline $\lg M^{l o}, \lg D^{\text {hi }}(F O)$ & $26.0 \pm 2.3(69.3)$ & $13.1 \pm 0.8(55.3)$ & $11.6 \pm 0.1(69.6)$ & $5.3 \pm 0.7(50.0)$ & $16.7 \pm 0.6(68.8)$ & $21.0 \pm 1.7(53.0)$ \\
\hline $\lg M^{h i}, \lg D^{h i}(T 2)$ & $4.6 \pm 0.9(12.3)$ & $4.3 \pm 0.5(18.2)$ & $1.5 \pm 0.3(9.3)$ & $1.6 \pm 0.5(14.6)$ & $3.1 \pm 0.9(12.8)$ & $8.2 \pm 0.2(20.7)$ \\
\hline $\lg M^{h i}, \lg D^{10}(T 1)$ & $3.1 \pm 0.5(8.3)$ & $2.4 \pm 0.3(9.8)$ & $0.9 \pm 0.2(5.2)$ & $1.1 \pm 0.1(10.5)$ & $1.3 \pm 0.1(5.2)$ & $3.9 \pm 1.1(9.9)$ \\
\hline $\mathrm{CD} 21^{\text {hi }} \mathrm{CD} 23^{\mathrm{lo}}$ (MZB) & $3.6 \pm 0.6(9.6)$ & $4.3 \pm 0.5(18.4)$ & $2.2 \pm 0.2(13.2)$ & $2.7 \pm 0.3(25.7)$ & $1.6 \pm 0.4(6.6)$ & $5.2 \pm 1.2(13.1)$ \\
\hline $\mathrm{CD} 21^{\text {int }} \mathrm{CD} 23^{\mathrm{hi}}$ (FO) & $29.8 \pm 0.8(79.5)$ & $13.2 \pm 2.7(59.1)$ & $11.6 \pm 1.9(70.0)$ & $5.5 \pm 0.9(52.0)$ & $20.6 \pm 0.2(84.9)$ & $23.9 \pm 1.3(60.2)$ \\
\hline $\mathrm{CD} 21^{\mathrm{lo}} \mathrm{CD} 23^{\mathrm{lo}}(\mathrm{NF})$ & $3.4 \pm 0.7$ (9.1) & $3.9 \pm 2.6(17.5)$ & $2.5 \pm 0.2(15.1)$ & $2.2 \pm 0.9(20.5)$ & $1.9 \pm 0.5(7.8)$ & $10.0 \pm 0.1(25.3)$ \\
\hline $\lg \mathrm{M}^{\mathrm{hi}} \lg \mathrm{D}^{\mathrm{lo}} \mathrm{CD} 21^{\mathrm{lo}}(\mathrm{NF})$ & $2.0 \pm 0.3(5.2)$ & $2.3 \pm 0.3(8.0)$ & ND & ND & ND & ND \\
\hline $\lg M^{h i} \lg D^{h i} C D 21^{\text {int }}(F O I I)$ & $3.4 \pm 0.6(9.1)$ & $3.6 \pm 0.8(13.1)$ & ND & ND & ND & ND \\
\hline $\lg M^{\operatorname{lo}} \lg D^{h i} C D 21^{\text {int }}(F O)$ & $24.3 \pm 2.4(66.0)$ & $14.6 \pm 2.0(53.0)$ & ND & ND & ND & ND \\
\hline $\lg M^{h i} \lg D^{h i} C D 21^{h i}(M Z P)$ & $1.7 \pm 0.4(4.5)$ & $1.5 \pm 0.3(5.5)$ & ND & ND & ND & ND \\
\hline $\lg M^{h i} \lg { }^{l o} C D 21^{h i}(M Z)$ & $4.4 \pm 0.8(11.2)$ & $4.7 \pm 0.5(16.2)$ & ND & ND & ND & ND \\
\hline $\begin{array}{l}\mathrm{CD}^{+} \\
\mathrm{F} 4 / 80^{+}\end{array}$ & $\begin{array}{c}21.3 \pm 1.4 \\
0.9 \pm 0.1\end{array}$ & $\begin{array}{r}13.8 \pm 0.6 \\
0.9 \pm 0.1\end{array}$ & $\begin{array}{c}15.0 \pm 0.7 \\
2.1 \pm 1.4\end{array}$ & $\begin{array}{c}10.4 \pm 0.5 \\
3.0 \pm 0.7\end{array}$ & $\begin{array}{c}15.8 \pm 1.2 \\
1.1 \pm 0.3\end{array}$ & $\begin{array}{c}23.6 \pm 3.3 \\
1.0 \pm 0.2\end{array}$ \\
\hline CD94 $4^{+}$CD3- & $1.0 \pm 0.3$ & $1.0 \pm 0.1$ & ND & ND & ND & ND \\
\hline $\mathrm{CD} 16 / \mathrm{CD} 2^{+} \mathrm{B}^{2} 20^{-}$ & $4.3 \pm 1.3$ & $4.4 \pm 1.1$ & ND & ND & ND & ND \\
\hline
\end{tabular}

Cell numbers are stated at $\times 10^{6}$. Values represent the mean \pm SD. For B cell subsets, the percentage of each subset in B220 $0^{+}$gated cells is given in parenthesis. AUF1-deficient and wild-type mice used for this analysis were 11-16 weeks of age. ND; not determined.

the percentage of transitional B cells (from $20.6 \%$ to $28.0 \%$ ) and MZ B cells (from 9.6\% to 18.4\%) whereas, in contrast, there was a decrease in the proportion of mature FO B cells (from 69.3\% to 55.4\%). As expected with a decrease in splenic FO B cells, there was a decrease in recirculating mature $\operatorname{IgM}^{\mathrm{lo}} \operatorname{IgD}^{\text {hi }} \mathrm{B}$ cells in the bone marrow and lymph node of AUF1-deficient mice (Figure 1a). An analysis of the third mature $B$ cell population, $\mathrm{CD} 5{ }^{\mathrm{hi}} \operatorname{IgM}^{\mathrm{hi}} \mathrm{B}-1$ cells in the peritoneum, showed no differences between wild type and AUFI ${ }^{-1-}$ animals (Figure 1a). All surface markers analyzed were expressed normally in AUF1-deficient splenic B cells, with the exception of $\mathrm{CD} 23$, which exhibited reduced expression (Figure 1c). Flow cytometric analysis of CD4, CD8, CD44, and CD62L surface markers of $\mathrm{T}$ cells in the spleen showed no differences (Figure 1a), suggesting that the nearly two-fold reduction in splenic $\mathrm{T}$ cells was not restricted to a defined $\mathrm{T}$ cell population.

Given the specific loss of FO B cells, we examined the expression of AUF1 in different B cell subsets. Surprisingly, flow cytometric analysis demonstrated that AUF1 expression was greatest in wild type MZ and T2 B cells, two populations whose absolute numbers were unaffected in $\mathrm{AUF}^{-1-}$ mice (Figure 1d). AUF1 consists of a family of four protein isoforms that are translated from an alternatively spliced mRNA [27]. Thus, we sorted B cell subsets and then analyzed AUF1 expression by immunoblot analysis to examine individual isoform expression. Consistent with the flow cytometery results, immunoblot analysis demonstrated that AUF1 was most strongly expressed in T2 B cells and MZ B cells. Differences in isoform expression were evident with T2 B cells exhibiting a relative increase in the expression of the p45 isoform. Surprisingly, FO B cells, which were significantly reduced in AUF1-deficient mice, expressed AUF1 at lower levels than other B cell subsets. These findings suggest that a FO B cell-independent process may be responsible for increased loss, such as through regulation of survival factors. Nevertheless, we cannot exclude the possible importance of an altered ratio of AUFI isoform expression, as previously suggested [28].

Loss of FO B cells is due to absence of AUF1 expression in the hematopoietic lineage

To determine whether the differences observed in splenic B cell subsets in $A U F 1^{-1-}$ mice were dependent on the expression of AUF1 in hematopoeitic cells, we performed bone marrow adoptive transfer studies. An equal number of bone marrow cells from AUF1-deficient or wild-type mice were transferred into sub-lethally irradiated $\mathrm{RAG}^{-1-}$ mice, which are devoid of mature $\mathrm{B}$ and $\mathrm{T}$ lymphocytes. Ten weeks after cell transfer, the $\mathrm{RAG1}^{-1-}$ recipient mice of AUF1 ${ }^{-1-}$ bone marrow, similar to $\mathrm{AUF}^{-1-}$ mice, exhibited a greater than two-fold reduction in number of splenic FO B cells and a sharp 
(a)

(a)

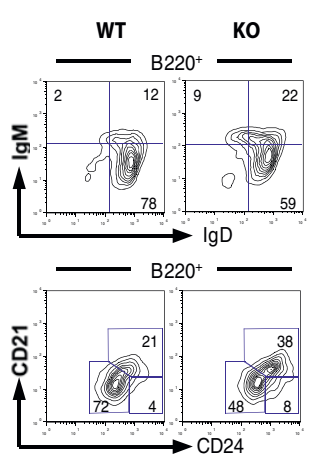

SP
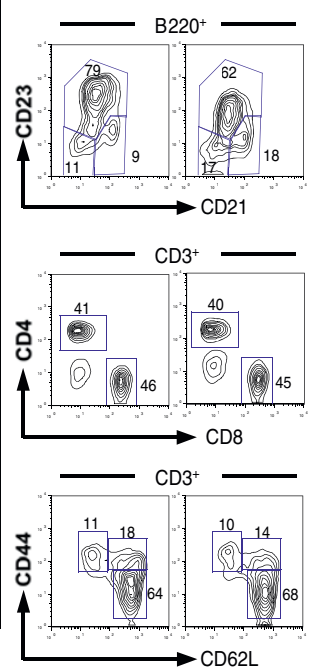

wT
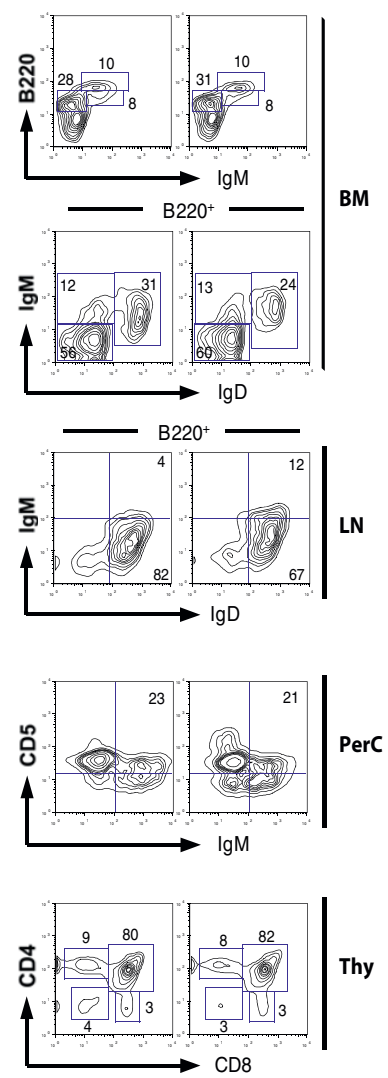
BM (b) WT B2 要

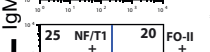

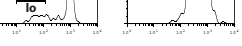
FO-II + MZP gate
$\lg \mathrm{M}^{\mathrm{hi}} \operatorname{IgD} \mathrm{Di}^{\mathrm{hi}}$

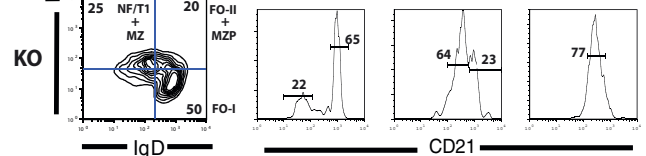

(c)

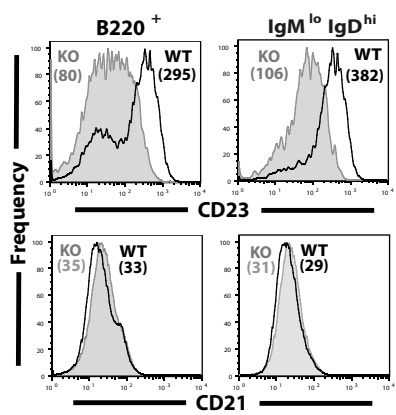

(d)

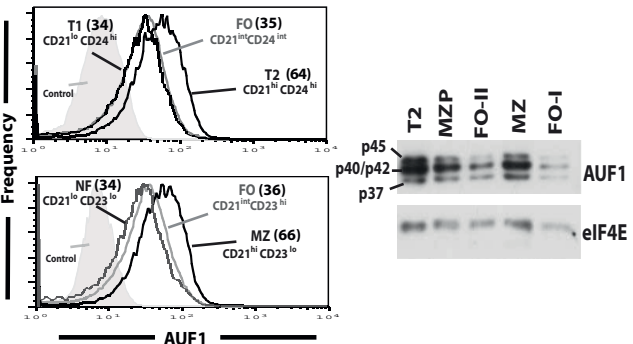

Figure 1 Flow cytometric analysis of lymphocyte populations in AUF1 ${ }^{-1-}$ mice. (a) Single cell suspensions from spleen (SP), bone marrow $(B M)$, lymph node (LN), peritoneal cavity (PerC), and thymus (Thy) of $\mathrm{AUF1}^{-1-}(\mathrm{KO})$ and wild-type (WT) littermates were stained with the indicated antibodies and analyzed. Numbers indicate the percentage of lymphoid cells in quadrants or enclosed within indicated gates. Contour plots gated for $\mathrm{B}_{220^{+}}$or $\mathrm{CD}^{+}$lymphocytes are indicated. Note decrease in $\mathrm{FO} B$ cells in $\mathrm{AUF} 1^{-1}$ spleens as represented by $\lg \mathrm{D}^{\mathrm{hi}} \operatorname{lgM} \mathrm{M}^{\mathrm{lo}}, \mathrm{CD} 21^{\mathrm{int}} \mathrm{CD} 24^{\mathrm{lo}}$, or $\mathrm{CD} 21^{{ }^{\text {int }} \mathrm{CD} 23^{\text {hi }}}$ gates. There is also an increase in the proportion of MZ B cells in KO spleens as represented by $\mathrm{CD} 21^{\text {hi }} \mathrm{CD} 23^{\text {lo }}$ gate. (b) Splenic B cells were analyzed for lgD and lgM expression (left panels) and gated populations were then analyzed for CD21 expression (right panels). This

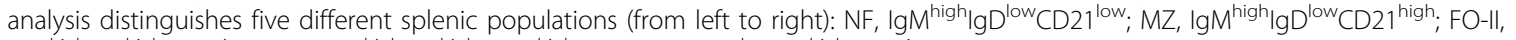

$\lg ^{\text {high }} \lg D^{\text {high }} C D 21^{\text {int, }}$ MZP, IgM ${ }^{\text {high }} \lg D^{\text {high }} C D 21^{\text {high }}$; and FO-l, IgM ${ }^{\text {low }} \lg D^{\text {high }} C D 21^{\text {int }}$. Three mice were analyzed in each group. (c) Decreased CD23 expression in AUF $1^{-1-}$ B cells $\left(B 220^{+}\right)$and FO B cells $\left(\mathrm{IgM}^{\mathrm{lo}} \mathrm{lg} \mathrm{D}^{\mathrm{hi}}\right.$ ) from AUF1 $1^{-1-}$ mice. (d) AUF1 expression in B cell subsets as determined by FACS (left panels) or immunoblot analysis (right panels). In immunoblot analysis, the staining with AUF1 shows three bands corresponding to the four isoforms of AUF1, and level of elF4E is shown as a control. Numbers in parenthesis in (c) and (d) depict mean fluorescence intensity (MFI).

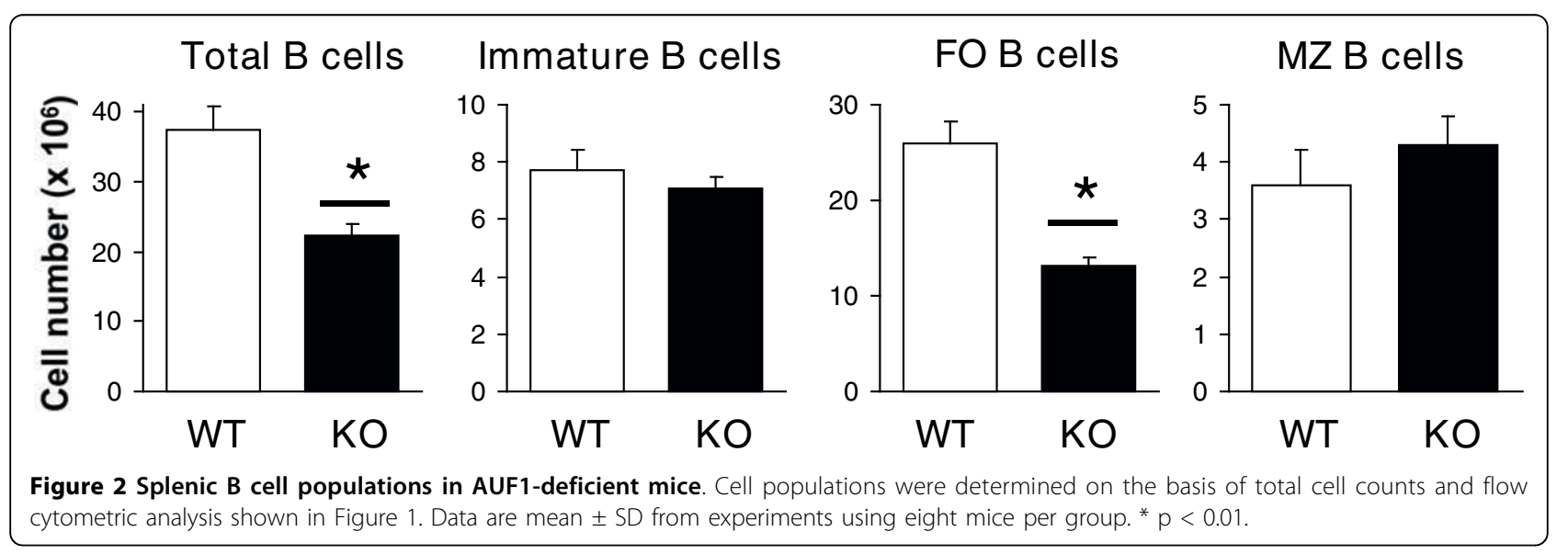


decrease in the proportion of FO B cells (from $69.6 \%$ to $50.0 \%$ ) as compared to $\mathrm{RAG}^{-1-}$ recipient mice of wildtype bone marrow (Figure 3a, Table 1). Similarly, irradiated wild-type mice reconstituted with AUF1 ${ }^{-1-}$ bone marrow exhibited a reduction in the proportion of FO B cells (from $68.8 \%$ to $53.0 \%$ ) as compared to irradiated $\mathrm{AUF}^{-1-}$ mice reconstituted with wild-type bone marrow (Figure 3a, Table 1). Irradiated $\mathrm{RAG1}^{-1-}$ or wildtype recipients of $A U F 1^{-1-}$ bone marrow, similar to $\mathrm{AUF1}^{-1-}$ mice, showed a reduction in CD23 expression (Figure $3 b$ ). These data demonstrate that changes in the frequency of mature B cells and decreased CD23 expression in $\mathrm{AUF}^{-1-}$ mice are intrinsic to the hematopoeitic lineage.

Decreased number of splenocytes in adult AUF ${ }^{-/-}$mice is not rescued by transfer of wild-type bone marrow

$\mathrm{AUF1}^{-1-}$ mice have much smaller spleens that support roughly half the number of splenocytes as compared to wild-type littermates (Figure 4; $70.8 \pm 10.7$ vs $41.6 \pm$ $\left.7.6 \times 10^{6}\right)$. To investigate if the decreased cellularity was dependent on AUF1 expression in the hematopoeitic population, bone marrow adoptive transfer experiments

\section{(a)}
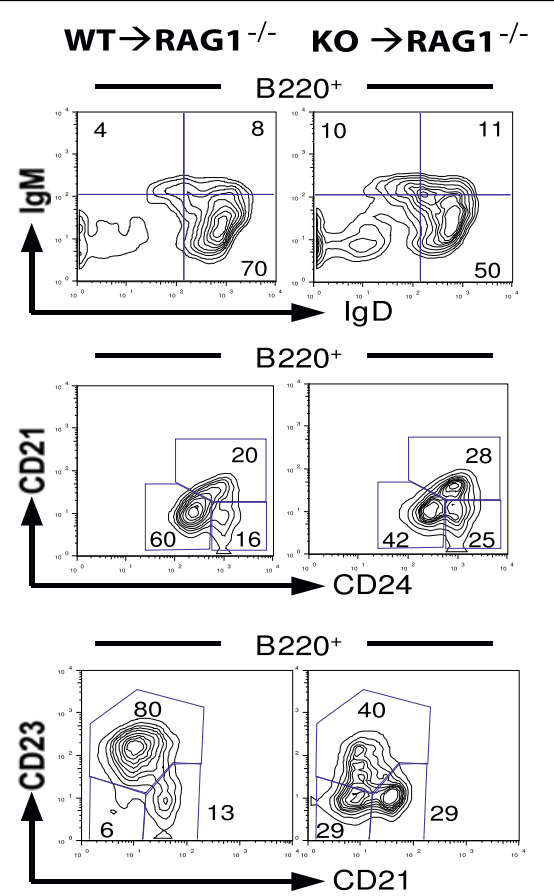

(b)

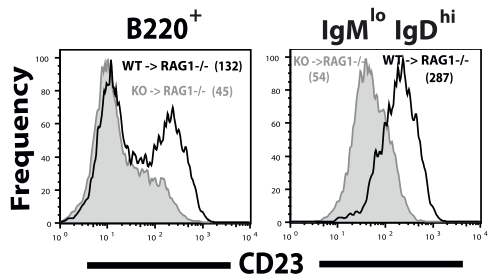

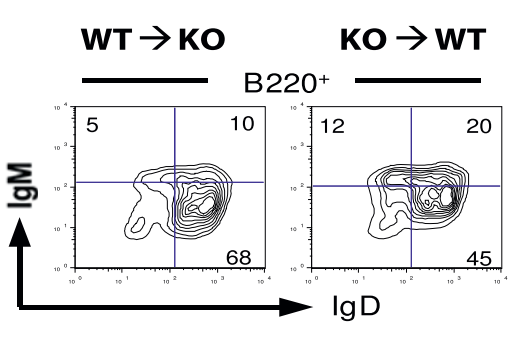
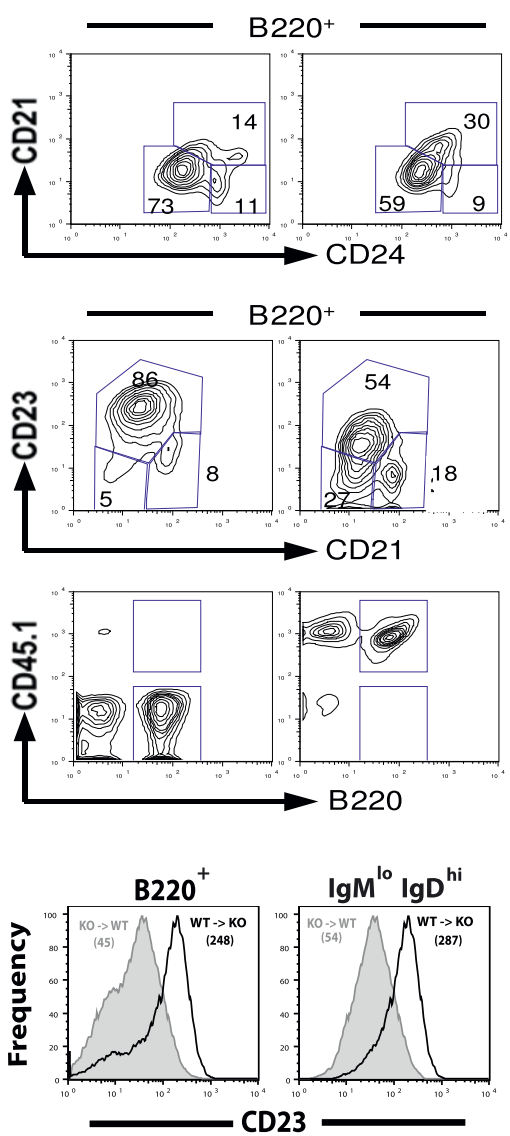

Figure 3 Flow cytometric analysis of lymphocyte populations in bone marrow chimeric mice. (a) Ten weeks post bone marrow transplantation, splenocytes from indicated bone marrow chimeric mice were stained with the indicated antibodies and analyzed. Numbers indicate the percentage of lymphoid cells in quadrants or enclosed within indicated gates. Contour plots gated for $\mathrm{B} 22 \mathrm{O}^{+}$are indicated. $\mathrm{FO} B$ cells are represented by $\lg D^{\text {hi }} \operatorname{lgM}{ }^{l o}, C D 21^{\text {int }} C D 24^{l o}$, and $C D 21^{\text {int }} C D 23^{\text {hi }}$ gates and MZ B cells are represented by the $C D 21^{\text {hi }} C D 23^{l o}$ gate. Splenocytes in bone marrow chimeras are of donor origin as shown by CD45 analysis. (b) Decreased CD23 expression in B cells (B220 ${ }^{+}$and FO $\mathrm{B}$ cells (lgM I IgD hi gated) from chimeric mice receiving bone marrow from AUF1 ${ }^{-1-}$ donors. Numbers in parenthesis indicate the MFI of CD23 expression. 


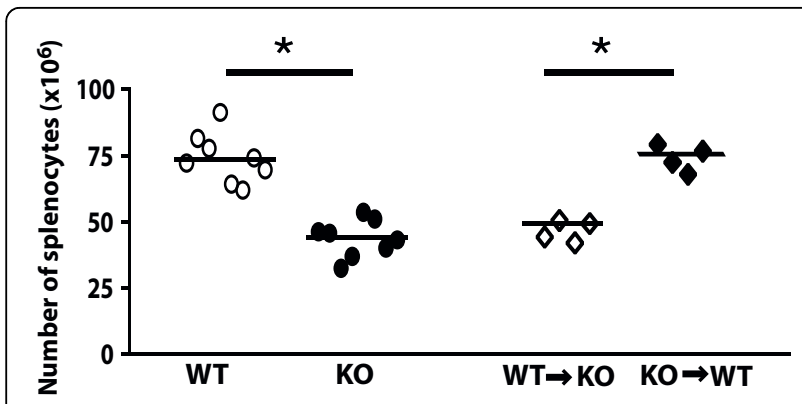

Figure 4 Number of splenocytes in $\mathrm{AUF}^{-/-}$mice and bone marrow chimeras. Each point represents cell counts from a single mouse as determined by hemocytometry. ${ }^{*} p<0.05$.

were performed. Surprisingly, irradiation of adult $\mathrm{AUF}^{-1-}$ mice and reconstitution with wild-type bone marrow did not rescue the reduction in splenic lymphocyte cellularity (Figure 4). Most simply these adoptive transfer studies suggest that the signals required for determining the number of splenic lymphocytes is likely provided by radiation-resistant stromal cells. However, we cannot rule out the possibility that these signals may be provided by the hematopoeitic lineage in a developmentally-fixed manner, similar to the mechanism described for the lymphotoxin signal needed in proper splenic organization $[29,30]$. Thus, these bone marrow transfer studies suggest that AUF1 influences two separate processes, since the transfer of wild-type bone marrow cells into $\mathrm{AUF}^{-1-}$ recipients corrects the proportion of FO and MZ B cells, but does not rescue the decreased number of splenocytes (Figure 4; Table 1). Similarly, transfer of AUF1 ${ }^{-1-}$ bone marrow cells into wild-type recipients results in a decreased proportion of FO B cells and increased proportion of MZ B cells, but does not alter the absolute number of splenocytes. Thus, we favor the hypothesis that AUF1 influences two separate processes: maintenance of the proportion of specific subsets of the mature B cell population. A function that is autonomous to AUF1 expression; and influencing the overall number of splenocytes, which is not autonomous to AUF1 expression in the hematopoeitic lineage.

Increased turnover of FO B cells in AUF1-deficient mice Mutations affecting either the production or survival of mature B cells can influence the number of B cells in the spleen [31]. Therefore, we next addressed whether the decrease in FO B cells in $\mathrm{AUF1}^{-1-}$ mice results from a defect in cell production and/or survival. Examination of B cell follicles in the spleens of AUF1-deficient mice revealed many pyknotic and fragmented cells characteristic of cells undergoing apoptosis (Figure 5a). The striking increase in the presence of apoptotic cells within the splenic follicles of AUF1 ${ }^{-1-}$ mice was confirmed by cleaved caspase- 3 staining (Figure 5a). Similarly, RAG1 ${ }^{-1-}$ mice reconstituted with AUF1 $1^{-1-}$ bone marrow exhibited pronounced apoptosis in splenic follicles (Figure 5b), a finding not seen in $\mathrm{RAG}^{-1-}$ mice reconstituted with wild-type bone marrow. BrdU pulsechase studies were performed to directly measure the turnover of FO B cells. Mice were continuously fed BrdU for 7 days and the proportion of BrdU-positive splenic FO B cells $\left(\mathrm{B} 220^{+} \mathrm{CD} 21^{\mathrm{lo}} \mathrm{CD} 24^{\mathrm{hi}}\right)$ was determined by flow cytometery at 0,7 , or 14 days following BrdU administration. At the end of the pulse period, a significantly greater proportion of FO B cells were labeled in $\mathrm{AUF1}^{-1-}$ mice as compared to wild-type littermates (Figure 5c). The percentage of $\mathrm{BrdU}^{+} \mathrm{FO} B$ cells stayed fairly stable for wild-type control mice during the chase period, but noticeably declined in $A U F 1^{-1-}$ mice (Figure 5c), demonstrating a two-fold decrease in the average half-life of $\mathrm{AUF1}^{-1-} \mathrm{B}$ cells (from 68 to 32 days). In contrast, BrdU pulse-chase studies demonstrated no differences in the labeling or turnover of MZ B cells in $\mathrm{AUF}^{-1-}$ mice (Figure 5c). It is well-established that the expression of Bcl-2 anti-apoptotic and pro-apoptotic family members is vital for the maintenance of B cells within the spleen [32]. Therefore, we assessed the levels of Bcl-2, A1, Bcl- $\mathrm{X}_{\mathrm{L}}$, and BIM mRNA in freshly sorted FO B cells from AUF1 ${ }^{-1-}$ and wild-type mice. AUF1-deficient FO B cells exhibited a significant decrease in all three anti-apoptotic factors (Figure $5 \mathrm{~d}$ ), with a $40 \%$ reduction in expression of $\mathrm{Bcl}-2$ and $\mathrm{Bcl}-\mathrm{X}_{\mathrm{L}}$ mRNAs and $65 \%$ reduction in A1 mRNA levels. However, no significant difference was seen in BIM mRNA levels in FO B cells from AUF1 ${ }^{\prime-}$ and wild-type mice. We further validated these results by comparing $\mathrm{Bcl}-2$ protein levels in mature splenic B cell populations of $A U F 1^{-1-}$ mice by flow cytometry. This analysis was restricted to Bcl-2 because it was not possible to measure $\mathrm{A} 1$ by flow cytometry. Consistent with a $40 \%$ decrease in Bcl-2 mRNA expression, the level of $\mathrm{Bcl}-2$ protein expression was similarly decreased in FO B cells from AUF1 $1^{-1-}$ mice (Figure 5e). In contrast, MZ B cells from $\mathrm{AUF}^{-1-}$ mice exhibited no difference in Bcl-2 expression as compared to MZ B cells from wild-type littermates (Figure 5e-f). We further characterized FO B cell turnover, by analyzing cell death in cultured cells via 7-AAD analysis. We purified FO B cells based on CD24 and CD21 markers, because purification with IgM and IgD could elicit BCR signals that influence B cell survival. FO B $\left(\mathrm{CD} 21^{\text {int }} \mathrm{C}\right.$ D24 $4^{\text {lo }}$ ) cells lacking AUF1 were more susceptible to spontaneous cell death in the first 36 hours in culture (Figure 5f). CD40 engagement has been shown to be important in the up-regulation of $\mathrm{Bcl}-2$ family members 
[33]. Thus, FO B cells were stimulated in culture by CD40 engagement to assess the ability to express Bcl-2 family members. AUF1-deficient FO B cells showed no differences in viability or in ability to express anti-apoptotic Bcl-2 family members upon CD40 engagement (Figure 5g). These data indicate that AUF1 deficiency leads to a decrease in FO B cell survival, presumably by impairing the expression of key survival factors Bcl-2, $\mathrm{Bcl}-\mathrm{X}_{\mathrm{L}}$, and $\mathrm{A} 1$ in absence of CD40 engagement.
No defect in $B C R$ signaling, in vitro maturation, or BAFF-R expression in AUF1 ${ }^{-/-}$B cells

To directly determine whether AUF1 plays a role in the development of FO B cells, we assayed the in vitro maturation of T2 B to FO B cells, as previously described [9]. BCR engagement on T2 B cells drives their differentiation to a mature $\mathrm{B}$ cell phenotype, as characterized by down-regulation of CD21 and CD24 surface expression. $\mathrm{B} 220^{+} \mathrm{CD} 21^{\mathrm{hi}} \mathrm{CD} 24^{\mathrm{hi}} \mathrm{T} 2$ splenocytes were sorted and 
cultured in the presence or absence of BCR stimulation and analyzed after $48 \mathrm{~h}$ (Figure 6a-b). Consistent with the BrdU studies, AUF1 ${ }^{-1-}$ T2 B cells exhibited no defect in maturation to a mature $\mathrm{B}$ cell phenotype in vitro (Figure 6b), suggesting that the BCR signaling pathway mediating this transition is unaffected by the absence of AUF1. AUF1 $1^{-/-}$B cells showed no differences in the duration or amplitude of $\mathrm{Ca}^{2+}$ flux (Figure 6c), cell size increase (data not shown), and up-regulation of the activation marker CD86 (Figure 6d) post-BCR ligation, as compared to wild-type B cells. These results therefore indicate that the proximal events of BCR-mediated signaling, shown to be vital in $\mathrm{B}$ cell maturation and survival $[13,16]$, are unaffected in AUF1 ${ }^{-/-}$B cells. BAFF, a member of the TNF superfamily, and its major receptor BAFF- $R$ have been shown to be critical in supporting transitional $\mathrm{B}$ cell maturation and enhancing the survival of mature B cells [34,35]. No differences were observed in the mRNA levels of BAFF-R in sorted FO AUF1 ${ }^{-1-} \mathrm{B}$ cells or in BAFF mRNA in AUF1 ${ }^{-1-}$ spleens as compared to wild-type controls (Figure 6e).

\section{Decreased T cell-independent humoral response} in $\mathrm{AUF}^{-/-}$mice

To determine the functional consequence of AUF1 deficiency, we next measured the ability of AUF1 $1^{-/-}$mice to mount a normal humoral immune response to antigenic challenge. TI antigen, TNP-Ficoll, or TD antigen, TNP$\mathrm{KLH}$, was injected intraperitoneally into $\mathrm{AUF} 1^{-/-}$and wild-type mice. Serum levels of TNP-specific antibodies were measured 7 and 14 days post-immunization with TNP-Ficoll and TNP-KLH, respectively. In the absence of antigenic challenge, we observed no differences in basal serum Ig levels between AUF1 ${ }^{-1-}$ and wild-type mice (Figure 7a, 7c). Consistent with this finding, we observed no differences in architecture or number of germinal centers (Figure 7a, 7d) or follicular dendritic network (Figure 7b) in spleens of $A U F 1^{-1-}$ mice. However, AUF $1^{-/-}$spleens showed distortion of distinct B (a)

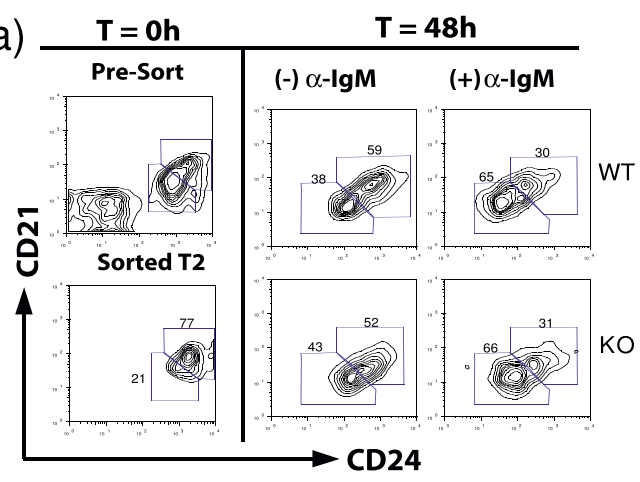

(c)

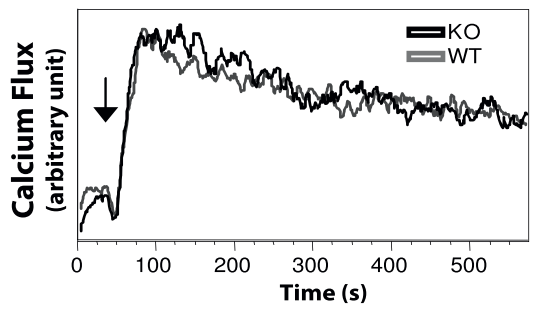

(b)

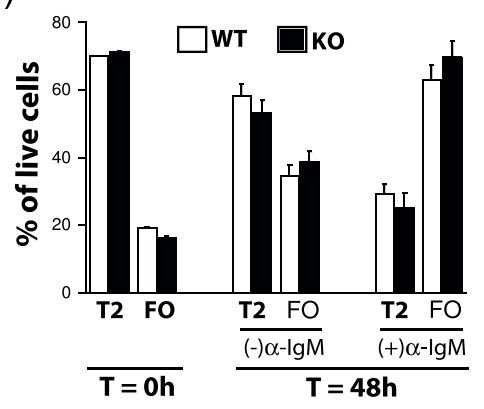

(d)

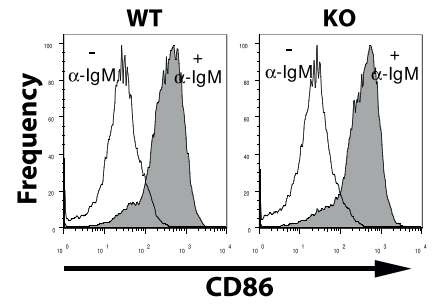

(e)
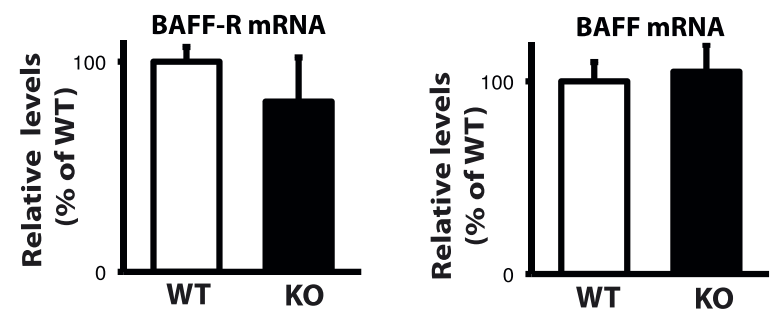

Figure 6 Normal in vitro maturation and BCR signaling in AUF1-deficient B cells. (a) Sorted T2 B cells (B220 ${ }^{+} C D 21^{\text {hi }} C D 24^{\text {hi }}$ ) were cultured with (+) or without (-) F(ab') $)_{2}$ anti-lgM $(10 \mu \mathrm{g} / \mathrm{ml})$ for $48 \mathrm{~h}$, and then analyzed by flow cytometry for CD21 and CD24 expression. (b) The percentage of live cells falling into T2 (CD21 $\left.{ }^{\text {hi }} \mathrm{CD} 24^{\mathrm{hi}}\right)$ and FO $\left(\mathrm{CD} 21^{\text {int }} \mathrm{CD} 24^{\mathrm{lo}}\right)$ gates are shown; mean $\pm \mathrm{SD}, n=3$. (c) Calcium flux analysis in response to BCR cross-linking. Arrow indicates time at which anti-lgM $(10 \mu \mathrm{g} / \mathrm{ml})$ was added to cells. (d) CD86 upregulation in B cells with (gray) or without (white) stimulation with $F\left(a b^{\prime}\right)_{2}$ anti-lgM. Data in $(c-d)$ is representative of three independent experiments. (e) mRNA levels of BAFF-R in sorted FO B cells (left panel) and BAFF in splenocytes (right panel) as determined by qRT-PCR. 

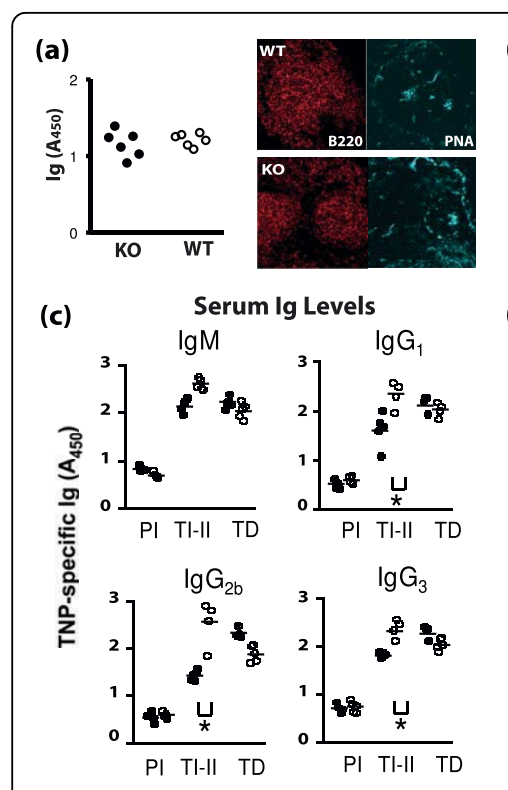

(b)

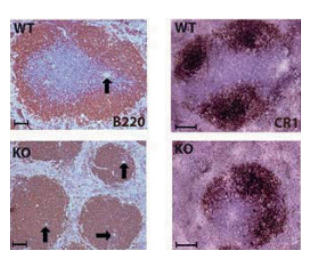

(d)

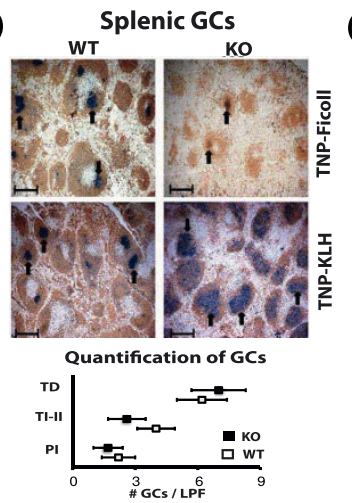

(e)

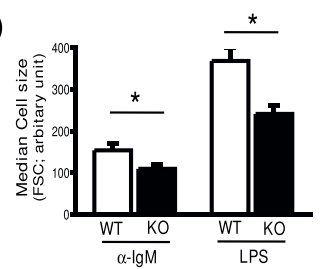

(g)

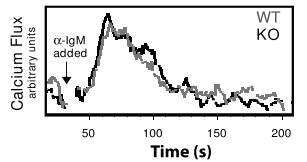

(h) Class-specific transcript mRNA

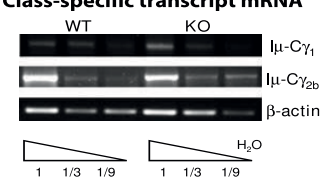

(f)

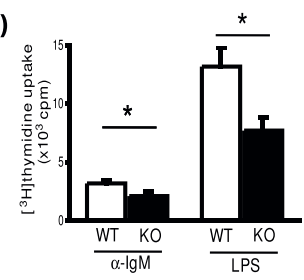

(i) In vitro immunoglobulin production

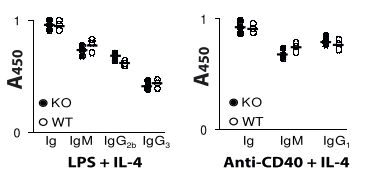

Figure 7 Impaired T-cell independent humoral response in AUF1 ${ }^{-1-}$ mice. (a) Total serum immunoglobulin levels in naïve mice. Each point represents the value obtained from an individual mouse, $A U F 1^{-1-}$ (black) or wild-type (white); $n=6$. Naiive spleens were stained for B cells (B220) and germinal centers (PNA). (b) B cell follicles were visualized by antibody to B220 and arrows indicate splenic arterioles. Follicular dendritic cells were visualized by antibody to CR1. Scale bar $=0.1 \mathrm{~mm}$. (c) Serum immunoglobulin (Ig) levels in naïve mice (preimmune, PI), and in mice post immunization with TNP-Ficoll (TI-II) or TNP-KLH (TD). Each point represents the value obtained from an individual mouse, AUF ${ }^{-1-}$ (black) or wildtype (white); $n=5,{ }^{*} p<0.05$. (d) Spleen sections from immunized wild-type and AUF1 ${ }^{-1-}$ mice were stained for B cells with anti-B220 (brown) and peanut agglutinin (PNA; blue) to visualize germinal centers (GCs, arrows). Scale bar $=0.5 \mathrm{~mm}$. Numbers of GCs per lower power field (LPF, 10X) were quantified. Values represent means from 5 mice (5 fields per mouse) \pm SD. (e) Median cell size and ( $f$ ) proliferation response to anti$\operatorname{lgM}(10 \mu \mathrm{g} / \mathrm{ml})$ or LPS $(10 \mu \mathrm{g} / \mathrm{ml})$ in sorted MZ B cells. Plots represent mean $\pm \mathrm{SD}, n=3 ;{ }^{*} p<0.05$. (g) Calcium flux analysis in response to BCR cross-linking. Arrow indicates time at which anti-lgM $(10 \mu \mathrm{g} / \mathrm{ml})$ was added to cells. Data is representative of three independent experiments. (h) RT-PCR directed at amplifying post-switch targets composed of $1 \mu$ exon spliced onto the $5^{\prime}$ exon of $C \gamma_{1}$ and $C \gamma_{2 b}$ gene or $\beta$-actin gene control performed on B cells stimulated with LPS + IL-4 for 4 days. (i) Total secreted immunoglobulin (lg) levels or indicated isotypes in culture supernatants from $B$ cells stimulated with LPS + IL-4 or anti-CD $40+I L-4$ for 4 days as determined by ELISA.

and $\mathrm{T}$ cell zones, as B cells are seen in PALS, a T cell area largely devoid of $\mathrm{B}$ cells in spleens from wild-type mice (Figure $7 \mathrm{~b}$ ). AUF1 $^{-1-}$ mice mounted a robust TD humoral response to immunization with TNP-KLH, consistent with the presence of very large germinal centers in the center of B cell follicles, where $\mathrm{T}$ cells normally reside (Figure $7 \mathrm{~d}$ ). Given the decrease in the number of FO B cells, one might have expected attenuation rather than augmentation of the TD humoral response. This discrepancy may stem from organizational defects that lead to aberrant germinal centers in the PALS in $\mathrm{AUF}^{-1-}$ mice. It may also reflect the increased $\mathrm{T}$ cell response as a result of aberrant control of IL-2 in $\mathrm{AUF}^{-1-}$ mice [36]. In contrast, $\mathrm{AUF1}^{-1-}$ mice showed a decreased humoral response to a TI antigen, TNP-Ficoll (Figure 7a). Given the importance of MZ B cells in an effective TI humoral response [37], we cannot rule out that AUF1 is important for proper MZ B cell function, especially given the high relative expression of AUF1 in this population (Figure 1d). This is supported by attenuation of cell size increase and attenuated proliferative response to $\mathrm{BCR}$-ligation and
LPS in AUF1-deficient MZ B cells as compared to wildtype controls (Figure 7e-f). There was no difference in calcium flux post-BCR ligation in MZB cells (Figure 7g), which suggests that the impact of AUF1 on MZ B cell function is downstream of calcium mobilization.

It has been suggested that as part of the LR1 transcription complex, AUF1 may play a role in heavy chain class switch recombination (CSR) [38]. Isotype CSR requires the transcription of class-specific mRNAs [39]. RT-PCR directed at amplifying post-switch targets composed of the $I_{\mu}$ exon spliced onto the $5^{\prime}$ exon of the $C \gamma_{1}$ and $C \gamma_{2 b}$ gene, loci reported to bind LR1 with the highest affinity [40], was performed on purified cultured B cells 4 days post-activation. $\mathrm{AUF1}^{-1-} \mathrm{B}$ cells did not display any defect in class-specific transcripts (Figure $7 \mathrm{~h}$ ). Furthermore, AUF $^{-1-}$ B cells cultured in the presence of IL-4 and either LPS or an antibody to CD40 exhibited no defect in the in vitro production of serum Igs (Figure 7i), indicating that AUF1 does not play a direct role in CSR activity in B cells. However, we cannot rule out that AUF1 may play an indirect role in proper humoral responses in vivo 
through the regulation of key cytokines important in CSR and immunoglobulin production.

\section{Discussion}

Our results show that AUF1 deficiency leads to a disturbance in mature splenic $B$ cell populations and in humoral immune responses. Past studies of mice with defective BCR signaling have demonstrated that the strength of the BCR signal is important in both maturation and determination of the cell-fate of the immature $B$ cells $[2,11,15]$. Furthermore, these studies collectively indicate that weak BCR signals favor MZ B cell development, whereas relatively strong signals favor the development of FO B cells, and perhaps even stronger signals favor the generation of $\mathrm{B} 1$ cells [11]. Our results indicate that the reduction of $\mathrm{B}$ cell numbers is specific to FO B cells, as normal numbers of T1, T2, FO-II, MZP, and MZ B cells are seen in spleens of AUF1 ${ }^{-1-}$ mice, as well as in irradiated $\mathrm{RAG}^{-1-}$ mice reconstituted with $\mathrm{AUF}^{-1-}$ bone marrow. These data suggest that there is no developmental block, nor are transitional B cells diverted to the mature $\mathrm{MZ} B$ cell population at the expense of FO B cells, in contrast to mice with impaired BCR signaling [11]. In agreement with this hypothesis, there is no impairment in production of FO B cells in vitro as shown by maturation assays, or in vivo as demonstrated by BrdU labeling studies. Overall, we conclude that development of FO B cells is unaffected in $\mathrm{AUF}^{-1-}$ mice. In addition to its role in development, signals processed by the BCR complex are required for mature $B$ cells to survive in the periphery. The specific loss of FO B cells in AUF1 ${ }^{-1-}$ mice does not seem to result from abnormal $\mathrm{BCR}$ signaling, as downstream events of BCR engagement, such as calcium mobilization are unaffected in $\mathrm{AUF}^{-1-} \mathrm{B}$ cells.

The phenotype seen in $\mathrm{AUF}^{-1-}$ mice does not seem to involve BAFF signaling, which has been shown to be important in both B cell development and homeostasis $[34,35]$. BAFF, a member of the TNF superfamily, and its receptors, BR3 and TACI, are not encoded by ARE-mRNAs and are therefore unlikely to be direct targets of AUF1. As predicted, no difference was observed in the expression of BAFF or its receptor in AUF1-deficient mice. Furthermore, the phenotype of BAFF-deficient mice differs from that of AUF1 $1^{-1-}$ mice. BAFF-deficient mice exhibit a loss of both $\mathrm{MZ}$ and FO B cells, as well as severely reduced antibody titers in response to both TD and TI antigens [34,41]. In contrast, AUF1 ${ }^{-1-}$ mice exhibit a selective loss of the FO B cell subset and a moderate attenuation of the TI humoral response. BAFF signaling is important in CD21 expression in B cells independent of its role in cell survival [41], and its regulation of $\mathrm{CD} 23$ expression is less clear. There are conflicting reports on the role of BAFF on CD23 expression from BAFF- deficient, BAFF-R-deficient, and transgenic BAFF mice [41-43]. In contrast, AUF1-deficient B cells show normal CD21 surface expression, but exhibit a reduction in CD23 surface expression (Figure 1). Although direct functions of AUF1 cannot be ruled out, alterations in local factors such as interleukin-4 in part may explain the decrease in CD23 expression in AUF1 ${ }^{-1-}$ B cells [44]. CD23 expression on B cells is involved in antigen presentation and IgE response, as demonstrated by the enhanced IgE response elicited in CD23-deficent mice [45]. We have previously shown that $\mathrm{AUF}^{1 /-}$ mice have increased circulating IgE levels [36] that may be due to the reduced CD23 expression on AUF1deficient B cells.

In the periphery, a lymphocyte acquires survival signals through receptors for cytokines, antigens, and hormones $[8,46]$. Failure to adequately acquire such signals results in cell death and thus determines the size of the peripheral lymphocyte pools $[8,46,47]$. Although signaling through the $\mathrm{BCR}$ is required for the maintenance of mature splenic B cells [9], it is not the only requirement. The splenic microenvironment also plays an essential role in the maintenance of mature B cells [17]. However, knowledge regarding the nature and regulation of the splenic microenvironment is limited, particularly as it pertains to the accumulation and maintenance of splenic lymphocytes. Our work suggests that AUF1 is important in the regulation of survival signals needed for the maintenance of FO B cells within the spleen, as indicated by decreased Bcl-2, A1, and Bcl- $\mathrm{X}_{\mathrm{L}}$ levels. Spleens from $\mathrm{AUF}^{-1-}$ mice bear a strong resemblance to those of Bcl2-deficient mice in that they are smaller, show a loss of mature $\mathrm{B}$ and $\mathrm{T}$ cells, and show many apoptotic cells [32]. Mature recirculating $\operatorname{IgM}^{\mathrm{lo}} \operatorname{IgD}{ }^{\mathrm{hi}}$ FO B cells from lymph nodes of $\mathrm{AUF}^{-1-}$ mice exhibit no significant differences in Bcl-2 expression (see Additional file 1), suggesting that the survival signal provided in lymph nodes is unaffected by the absence of AUF1. These findings highlight differences in survival signals necessary for recirculating mature $B$ cells in different lymphoid organs. In support of this hypothesis, it has been recently shown that macrophage migration inhibitory factor (MIF), through the activation of the CD74-CD44 complex, is necessary in the maintenance of mature $\mathrm{B}$ cells in the bone marrow, but not in the spleen or lymph nodes [48]. The spleen-specific alterations in lymphocyte populations in AUF1 $1^{-1-}$ mice suggests that AUF1 acts in regulating the local microenvironment, as opposed to regulating global factors in lymphocyte development, such as BCR signaling that appears normal in $\mathrm{AUF}^{-1-} \mathrm{B}$ lymphocytes. Future studies with a more comprehensive screening approach, such as cDNA micro-arrays, may prove valuable in identifying mRNAs regulated by AUF1 that play a role in FO B cell lymphocyte survival within the spleen. CD40 engagement on 
mature B cells results in induction of anti-apoptotic Bcl2 family members, which protect these cells from antigen receptor-mediated apoptosis [33] and are required for GC formation, progression [49] and TD response [50]. AUF1 ${ }^{-1-}$ FO B cells were able to appropriately induce the expression of $\mathrm{Bcl}-2$ and $\mathrm{A} 1$ in response to CD40 engagement, which supports their ability to form germinal centers in AUF1-deficient mice.

An important phenotype of AUF1-deficiency is a decrease in the number of splenic lymphocytes and a skewing of the B cell subpopulations, with an over-representation of immature and MZ B cells and a decrease in FO B cells. There are several possible mechanisms that may account for this complex phenotype. AUF1 may regulate a survival signal needed for the maintenance of FO B cells, the largest component of splenic B cells, and loss of this population could lead to a decrease in the accumulation of $T$ cells within the spleen. Previous studies on $B$ cell-deficient mice have reported a decrease in splenic $\mathrm{T}$ cell numbers [30,51]. BCR-deficient mice exhibit a threefold reduction in the number of splenic CD4 and CD8 T cells, although no loss of $\mathrm{T}$ cells was seen in lymph nodes from these animals [30]. These results suggest that B cells provide signals that promote CD4 and CD8 $\mathrm{T}$ cell accumulation and/or survival in the spleen [30]. Notably, CD38- and CD4-deficient mice show a $40 \%$ reduction of splenic mature $B$ cells, suggesting that $\mathrm{T}$ cells may also impact the survival of B cells within the spleen [31]. Likewise, AUF1 may regulate survival signals required independently for the maintenance of FO B and T cells. At this time we cannot distinguish whether the loss of $\mathrm{T}$ and $\mathrm{B}$ cells within the spleen are related, or whether both populations, independent of each other, are deficient in survival signals, resulting in decreased $\mathrm{Bcl}-2$ expression in both populations in AUF1 ${ }^{-1-}$ mice (see Additional file 1). These mechanisms predict that the $50 \%$ decrease in splenic $\mathrm{B}$ cells in $\mathrm{AUF}^{-1-}$ mice results from increased FO B cell turnover that outpaces the rate of FO B cell production by two-fold. However, BrdU studies indicate that there is a 2.1 -fold decrease in splenic FO B cell average half-life and a 1.7-fold increase of $B$ cell production in $\mathrm{AUF}^{-1-}$ mice. This would result in a $30 \%$ decrease in FO $\mathrm{B}$ cells and not the $50 \%$ decrease observed in AUF1 ${ }^{-1-}$ mice. Furthermore, if turnover did outpace production by two-fold, one would predict a greater decrease than the $20 \%$ seen in recirculating mature B cells in lymph nodes and bone marrow of $\mathrm{AUF}^{-1-}$ mice.

The data from bone marrow adoptive transfer studies more likely indicate that two separate processes are involved in the observed phenotype: (1) AUF1 is important in the maintenance of FO B cells within the spleen, most likely through regulation of survival factors; and (2) AUF1 impacts the number of lymphocytes within the spleen through the regulation of yet unknown signals. Adoptive transfer studies support the involvement of two separate processes, as reconstitution of irradiated $\mathrm{AUF}^{-1-}$ mice with wild-type bone marrow corrects the shifts in B cell subpopulation proportions but not the overall number of splenocytes. The involvement of two separate processes also better explains the deficit in FO B cells. The $40 \%$ decrease in the number of splenocytes, in addition to the increased FO B cell turnover that would result in a $30 \%$ decrease in the proportion of FO B cells, more accurately approximates the $50 \%$ decrease in the number of FO B cells observed in $\mathrm{AUF1}^{-1-}$ mice.

The complex phenotype seen in AUF1-deficient mice is not surprising, given that AUF1 regulates the expression of numerous immune-modulating cytokines and chemokines $[20,36,52,53]$. Although we have focused here on defects in the B cell compartment in AUF1-deficient mice, we have previously shown defects in the $\mathrm{T}$ cell and macrophage compartments [36]. Moreover, despite the fact that the FDC network can be visualized, we cannot exclude that the dendritic subset may be affected in AUF1-deficient mice and may impact the function, size, and location of other immune cell compartments. Tristetraprolin, another ARE-binding protein, binds and regulates the expression of mRNAs encoding key regulators of human dendritic cell maturation [54]. Future analysis of specific targets of AUF1 in different immune cell subsets will be important in dissecting the role of AUF1 on individual populations leading to the overall complex phenotype seen in its deficiency in the mouse model.

\section{Conclusion}

This work demonstrates that AUF1 is important in determining the size of the splenic lymphocyte population and proper survival of FO B cells within the spleen. Future studies will address the identification and regulation of AUF1 targets as they pertain to splenic size, FO $B$ cell maintenance, and humoral immune response.

\section{Authors' information}

The authors declare no competing financial interests. Correspondence and requests for materials should be addressed to R.J.S. (Robert.Schneider@nyumc.org).

\footnotetext{
Additional file 1: $\mathrm{BCl}-2$ expression in $\mathrm{T}$ and $\mathrm{FO} \mathrm{B}$ cells from spleens and lymph nodes from AUF1 ${ }^{-/}$mice. Intracellular $\mathrm{BCl}-2$ protein levels in $\mathrm{FO} B, C D 4^{+} \mathrm{T}$, and $\mathrm{CD} 8^{+} \mathrm{T}$ cells from spleens and lymph nodes were determined by four-color flow cytometric analysis. Histograms depict the intensity of wild-type (bold) and AUF1 ${ }^{-/}$(shaded) cells stained with BCl-2 antibody or wild-type stained with isotype-matched control antibody (thin line). Bcl-2 expression was quantified. The normalized values (mean fluorescence intensity (MFI) for BCl-2 - MFI of isotype-matched control) for $\mathrm{AUF}^{-1}$ cells were plotted as a percentage of wild-type values. Plot represents mean \pm SD for four mice in each group. ${ }^{*} p<0.05$. Click here for file

[http://www.biomedcentral.com/content/supplementary/1471-2172-11-1S1.EPS]
} 


\section{Abbreviations}

7-AAD: 7-amino-actinomycin D; ARE: adenosine/uridine-rich element; BCR: B cell receptor; BAFF: B cell activating factor; FO: follicular; GC: germinal center; MFI: mean fluorescence intensity; MZ: marginal zone; PALS: periarteriolar lymphoid sheath; T1: transitional type-1; T2: transitional type-2; TI: T-cell independent; TD: T-cell dependent

\section{Acknowledgements}

We thank Dr. Doris Tse at the Center for Aids Research at NYU School of Medicine for assistance in FACS analysis, and the NYU Histology Core Facilities for assistance in preparing slides. We thank Drs. Michael Dustin, Dan Littman, and Jane Skok for their insights in the preparation of this manuscript. This work was supported by a grant from the NIH (R.J.S.) and an $\mathrm{NIH}$ T32 training grant (N.S.)

\section{Author details}

'Department of Microbiology, New York University School of Medicine, 550 First Avenue, New York, NY 10016, USA. ²BCMM 231, Howard Hughes Medical Institute, Yale University School of Medicine, 295 Congress Ave, New Haven, CT 06536, USA

\section{Authors' contributions}

NS made substantial contributions to conception and design of the study, acquired, analyzed, and interpreted the data, and drafted the manuscript. RJS contributed in data analysis and writing of the manuscript. $J \mathrm{~L}$ and MB made contributions to the study design and acquisition of data. All authors read and approved the final manuscript.

\section{Received: 30 April 2009}

Accepted: 11 January 2010 Published: 11 January 2010

\section{References}

1. Mebius RE, Kraal G: Structure and function of the spleen. Nat Rev Immunol 2005, 5:606-16

2. Loder F, Mutschler B, Ray RJ, Paige CJ, Sideras P, Torres R, Lamers MC, Carsetti R: B cell development in the spleen takes place in discrete steps and is determined by the quality of $B$ cell receptor-derived signals. J Exp Med 1999, 190:75-89.

3. Su TT, Guo B, Wei B, Braun J, Rawlings DJ: Signaling in transitional type 2 B cells is critical for peripheral B-cell development. Immunol Rev 2004, 197:161-78.

4. Martin F, Kearney JF: B-cell subsets and the mature preimmune repertoire. Marginal zone and B1 B cells as part of a "natural immune memory". Immunol Rev 2000, 175:70-9.

5. McHeyzer-Williams MG: B cells as effectors. Curr Opin Immunol 2003, 15: 354-61.

6. Martin F, Oliver AM, Kearney JF: Marginal zone and B1 B cells unite in the early response against T-independent blood-borne particulate antigens. Immunity 2001, 14:617-29.

7. Cariappa A, Boboila C, Moran ST, Liu H, Shi HN, Pillai S: The recirculating B cell pool contains two functionally distinct, long-lived, posttransitional, follicular B cell populations. J Immunol 2007, 179:2270-81.

8. Gaudin E, Rosado M, Agenes F, McLean A, Freitas AA: B-cell homeostasis, competition, resources, and positive selection by self-antigens. Immunol Rev 2004, 197:102-15.

9. Su TT, Rawlings DJ: Transitional B lymphocyte subsets operate as distinct checkpoints in murine splenic B cell development. J Immunol 2002, 168:2101-10.

10. Cornall RJ, Cheng AM, Pawson T, Goodnow CC: Role of Syk in B-cell development and antigen-receptor signaling. Proc Natl Acad Sci USA 2000, 97:1713-8.

11. Niiro H, Clark EA: Regulation of B-cell fate by antigen-receptor signals. Nat Rev Immunol 2002, 2:945-56.

12. Reichlin A, Hu Y, Meffre E, Nagaoka H, Gong S, Kraus M, Rajewsky K, Nussenzweig MC: $B$ cell development is arrested at the immature $B$ cell stage in mice carrying a mutation in the cytoplasmic domain of immunoglobulin beta. J Exp Med 2001, 193:13-23.

13. Torres RM, Flaswinkel $H$, Reth M, Rajewsky K: Aberrant B cell development and immune response in mice with a compromised BCR complex. Science 1996, 272:1804-8.
14. Yamazaki T, Takeda K, Gotoh K, Takeshima H, Akira S, Kurosaki T: Essential immunoregulatory role for BCAP in B cell development and function. $J$ Exp Med 2002, 195:535-45.

15. Pillai S, Cariappa A, Moran ST: Positive selection and lineage commitment during peripheral B-lymphocyte development. Immunol Rev 2004 197:206-18.

16. Lam KP, Kuhn R, Rajewsky K: In vivo ablation of surface immunoglobulin on mature $B$ cells by inducible gene targeting results in rapid cell death. Cell 1997, 90:1073-83.

17. Carsetti R, Rosado MM, Wardmann H: Peripheral development of $B$ cells in mouse and man. Immunol Rev 2004, 197:179-91.

18. Tangye SG, Hodgkin PD: Divide and conquer: the importance of cell division in regulating B-cell responses. Immunology 2004, 112:509-20.

19. Buzby JS, Brewer G, Nugent DJ: Developmental regulation of RNA transcript destabilization by A + U-rich elements is AUF1-dependent. J Biol Chem 1999, 274:33973-8.

20. Lu JY, Sadri N, Schneider RJ: Endotoxic shock in AUF1 knockout mice mediated by failure to degrade proinflammatory cytokine mRNAs. Genes Dev 2006, 20:3174-84.

21. Sarkar B, Xi Q, He C, Schneider RJ: Selective degradation of AU-rich mRNAs promoted by the p37 AUF1 protein isoform. Mol Cell Biol 2003, 23:6685-93.

22. Liao B, HU Y, Brewer G: Competitive binding of AUF1 and TIAR to MYC mRNA controls its translation. Nat Struct Mol Biol 2007, 14:511-8.

23. Lee C, Gyorgy A, Maric D, Sadri N, Schneider RJ, Barker JL, Lawson M, Agoston DV: Members of the NuRD Chromatin Remodeling Complex Interact with AUF1 in Developing Cortical Neurons. Cereb Cortex 2008, 18(12):2909-19.

24. Sadri N, Schneider RJ: Auf1/Hnrnpd-deficient mice develop pruritic inflammatory skin disease. J Invest Dermatol 2009, 129:657-70.

25. Lu JY, Schneider RJ: Tissue distribution of AU-rich mRNA-binding proteins involved in regulation of mRNA decay. J Biol Chem 2004, 279: 12974-9.

26. Muramatsu M, Kinoshita K, Fagarasan S, Yamada S, Shinkai Y, Honjo T: Class switch recombination and hypermutation require activation-induced cytidine deaminase (AID), a potential RNA editing enzyme. Cell 2000, 102:553-63.

27. Wagner BJ, DeMaria CT, Sun Y, Wilson GM, Brewer G: Structure and genomic organization of the human AUF1 gene: alternative pre-mRNA splicing generates four protein isoforms. Genomics 1998, 48:195-202.

28. Raineri I, Wegmueller D, Gross B, Certa U, Moroni C: Roles of AUF1 isoforms, HuR and BRF1 in ARE-dependent mRNA turnover studied by RNA interference. Nucleic Acids Res 2004, 32:1279-88.

29. Fu YX, Molina H, Matsumoto M, Huang G, Min J, Chaplin DD: Lymphotoxin-alpha (LTalpha) supports development of splenic follicular structure that is required for IgG responses. J Exp Med 1997, 185:2111-20.

30. Ngo VN, Cornall RJ, Cyster JG: Splenic T zone development is B cell dependent. J Exp Med 2001, 194:1649-60.

31. Rolink AG, Brocker T, Bluethmann H, Kosco-Vilbois MH, Andersson J, Melchers F: Mutations affecting either generation or survival of cells influence the pool size of mature B cells. Immunity 1999, 10:619-28.

32. Veis DJ, Sorenson CM, Shutter JR, Korsmeyer SJ: BCl-2-deficient mice demonstrate fulminant lymphoid apoptosis, polycystic kidneys, and hypopigmented hair. Cell 1993, 75:229-40.

33. Craxton A, Chuang PI, Shu G, Harlan JM, Clark EA: The CD40-inducible BCl2 family member $A 1$ protects $B$ cells from antigen receptor-mediated apoptosis. Cell Immunol 2000, 200:56-62.

34. Schiemann B, Gommerman JL, Vora K, Cachero TG, Shulga-Morskaya S, Dobles M, Frew E, Scott ML: An essential role for BAFF in the normal development of $B$ cells through a BCMA-independent pathway. Science 2001, 293:2111-4.

35. Thompson JS, Schneider P, Kalled SL, Wang L, Lefevre EA, Cachero TG, MacKay F, Bixler SA, Zafari M, Liu ZY, et al: BAFF binds to the tumor necrosis factor receptor-like molecule $B$ cell maturation antigen and is important for maintaining the peripheral B cell population. J Exp Med 2000, 192:129-35.

36. Sadri N, Schneider RJ: Hnrnpd -deficeint Mice Develop Pruritic Inflammatory Skin Disease. J Invest Dermatol 2008, 129:657-70.

37. Guinamard R, Okigaki M, Schlessinger J, Ravetch JV: Absence of marginal zone $B$ cells in Pyk-2-deficient mice defines their role in the humoral response. Nat Immunol 2000, 1:31-6.

38. Hanakahi LA, Maizels N: Transcriptional activation by LR1 at the Emu enhancer and switch region sites. Nucleic Acids Res 2000, 28:2651-7. 
39. Chaudhuri J, Alt FW: Class-switch recombination: interplay of transcription, DNA deamination and DNA repair. Nat Rev Immunol 2004, 4:541-52.

40. Hanakahi LA, Dempsey LA, Li MJ, Maizels N: Nucleolin is one component of the B cell-specific transcription factor and switch region binding protein, LR1. Proc Natl Acad Sci USA 1997, 94:3605-10.

41. Gorelik L, Cutler AH, Thill G, Miklasz SD, Shea DE, Ambrose C, Bixler SA, Su L, Scott ML, Kalled SL: Cutting edge: BAFF regulates CD21/35 and CD23 expression independent of its B cell survival function. J Immuno/ 2004, 172:762-6.

42. Debnath I, Roundy KM, Weis JJ, Weis JH: Analysis of the regulatory role of BAFF in controlling the expression of CD21 and CD23. Mol Immunol 2007, 44:2388-99.

43. Sasaki Y, Casola S, Kutok JL, Rajewsky K, Schmidt-Supprian M: TNF family member $B$ cell-activating factor (BAFF) receptor-dependent and -independent roles for BAFF in B cell physiology. J Immunol 2004, 173 : 2245-52.

44. Hudak SA, Gollnick SO, Conrad DH, Kehry MR: Murine B-cell stimulatory factor 1 (interleukin 4) increases expression of the Fc receptor for lgE on mouse B cells. Proc Natl Acad Sci USA 1987, 84:4606-10.

45. Lamers MC, Yu P: Regulation of IgE synthesis. Lessons from the study of IgE transgenic and CD23-deficient mice. Immunol Rev 1995, 148:71-95.

46. Khaled AR, Durum SK: Lymphocide: cytokines and the control of lymphoid homeostasis. Nat Rev Immunol 2002, 2:817-30.

47. Freitas AA, Rocha B: Population biology of lymphocytes: the flight for survival. Annu Rev Immunol 2000, 18:83-111.

48. Gore Y, Starlets D, Maharshak N, Becker-Herman S, Kaneyuki U, Leng L, Bucala R, Shachar I: Macrophage migration inhibitory factor induces B cell survival by activation of a CD74-CD44 receptor complex. J Biol Chem 2008, 283:2784-92

49. Foy TM, Laman JD, Ledbetter JA, Aruffo A, Claassen E, Noelle RJ: gp39CD40 interactions are essential for germinal center formation and the development of B cell memory. J Exp Med 1994, 180:157-63.

50. Foy TM, Shepherd DM, Durie FH, Aruffo A, Ledbetter JA, Noelle RJ: In vivo CD40-gp39 interactions are essential for thymus-dependent humoral immunity. II. Prolonged suppression of the humoral immune response by an antibody to the ligand for CD40, gp39. J Exp Med 1993, 178:156775.

51. Chan OT, Madaio MP, Shlomchik MJ: B cells are required for lupus nephritis in the polygenic, Fas-intact MRL model of systemic autoimmunity. J Immunol 1999, 163:3592-6.

52. Anderson P: Post-transcriptional control of cytokine production. Nat Immunol 2008, 9:353-9.

53. Sarkar S, Sinsimer KS, Foster RL, Brewer G, Pestka S: AUF1 isoform-specific regulation of anti-inflammatory IL10 expression in monocytes. J Interferon Cytokine Res 2008, 28:679-91.

54. Emmons J, Townley-Tilson WH, Deleault KM, Skinner SJ, Gross RH, Whitfield ML, Brooks SA: Identification of TTP mRNA targets in human dendritic cells reveals TTP as a critical regulator of dendritic cell maturation. RNA 2008, 14:888-902.

doi:10.1186/1471-2172-11-1

Cite this article as: Sadri et al: AUF1 is involved in splenic follicular B cell maintenance. BMC Immunology 2010 11:1.

\section{Submit your next manuscript to BioMed Central and take full advantage of:}

- Convenient online submission

- Thorough peer review

- No space constraints or color figure charges

- Immediate publication on acceptance

- Inclusion in PubMed, CAS, Scopus and Google Scholar

- Research which is freely available for redistribution 